\title{
Los libros parroquiales como fuentes complementarias para la historia de la Mixteca
}

\author{
Manuel A. Hermann Lejarazu
}

$\mathrm{E}$ n la iglesia de la actual Magdalena Jaltepec (comunidad que llegó a integrarse como parte de uno de los más importantes señoríos en la época prehispánica) se conservan en sus archivos numerosos documentos de gran valor histórico. Este conjunto de manuscritos conforma lo que se conoce como libros parroquiales, cuya información puede llegar a ser realmente valiosa en la construcción de la historia social y económica de diversas regiones.

Los libros parroquiales son, en su mayoría, los registros puntuales de bautizos, matrimonios, defunciones y de diversos sacramentos que realizan los curas o ministros religiosos que residen en alguna parroquia. A pesar de ser textos un tanto escuetos, cada registro va acompañado de información que bien puede aprovecharse para estudios de tipo genealógico, estadístico, económico y demográfico.

Aunque en la mayoría de las ocasiones los archivos parroquiales no suelen conservar toda su documentación histórica, al menos, en lo que respecta a la iglesia de Jaltepec, existen aún varios libros escritos a lo largo del siglo XVIII, por lo que existe un registro muy completo no sólo de la población de este lugar, sino también de otros pueblos que estaban sujetos a esta doctrina. En aquella época, la doctrina de Jaltepec estaba compuesta de cinco pueblos: San Andrés Nuxiño, San Mateo Etlatongo, Santa Inés, Santo Domingo Nuxaa y Santa María Añuhma, comunidades que, en su mayoría, son actualmente municipios o agencias municipales. No obstante, los habitantes de otros pueblos o ranchos solían acudir a la cabecera de Jaltepec a recibir la administración religiosa de parte de algún clérigo que residía ahí en ese momento.

Los siguientes testimonios fueron tomados de uno de los libros de bautizos que se conservan en la iglesia y que comprenden los años de 1703 a 1755. En este libro quedaron constancias de numerosos niños que recibieron este principal sacramento, junto con algunos datos de interés histórico que se señalarán a lo largo de los textos.

\section{Parochial Books as Complementary Sources for a History of the Mixteca}

MANUel A. Hermann LeJARAZU: Centro de Investigaciones y Estudios Superiores en Antropología Social-Distrito Federal, México. hermann@ciesas.edu.mx

* Quiero agradecer muy especialmente al profesor Manuel Miguel Robles y a Juan Miguel Zúñiga, presidente del Museo de Jaltepec, por las facilidades que me dieron para reproducir estos documentos. 


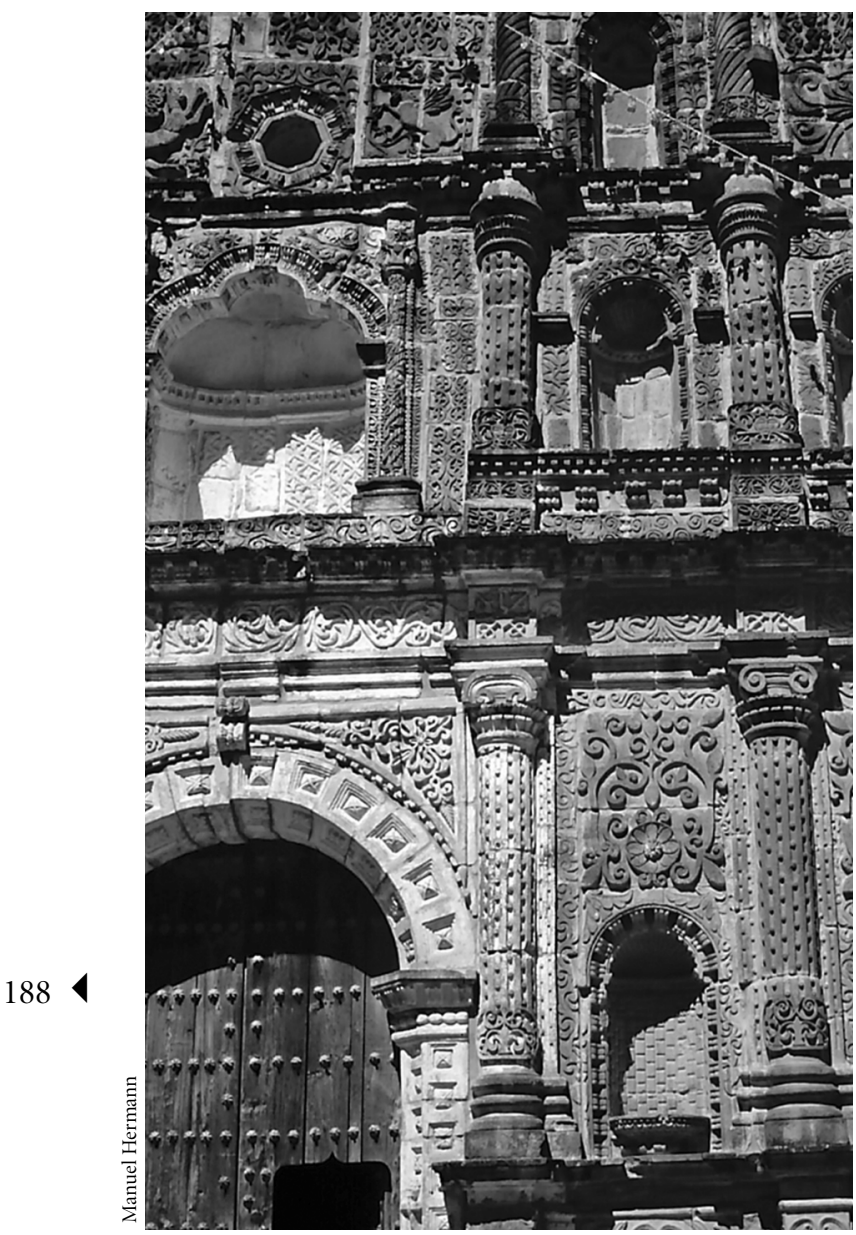

Iglesia de Santa María Tiltepec.

Presentaré a continuación la transcripción y paleografía de varias entradas del libro de bautizos que realicé bajo los siguientes criterios: se trató de conservar la ortografía original del texto, aunque se modernizó la acentuación y la puntuación en las palabras para una mejor comprensión de éstas. Se desataron las abreviaturas y se conservó la forma en que fueron escritos los topónimos debido a su importancia como material histórico-filológico.

Como ya he señalado, las entradas del libro de bautizos son muy breves, pero tienen información relevante relacionada con los habitantes de Jaltepec o de las poblaciones vecinas, como los nombres de los padres y padrinos del recién nacido, por ejemplo.

\section{Transcripción}

Foja $1 \mathrm{r}$.

\section{Año de 1703}

En el pueblo y cavezera de S[an]ta María Magdalena de Jaltepeque en treze días del mes de mayo de este presente año de mill setezientos y tres, yo fray Joseph de Thellechea cura ministro de esta d[ic]ha Doctrina bauptizé a María Michaela, que nació (el) día martes ocho de d[i]cho mes, hija de Thomas de la Cruz, Yndio, y de Nicolasa de Aillón, mulata: fueron sus padrinos Joseph Antonio y Catharina, mestizos, naturales de la ciudad de Guaxaca, y vezinos del pueblo de S[a]n Miguel Tecomatlán de la Doctrina del pueblo de Yanhuitlán: y p[or] q[ue] conste lo firmé

(Rúbrica)

Joseph de Thellechea

En el pueblo de S[a]n Matheo Yuqhnduchi en doze días del mes de junio de mill setecientos y tres a[ños], yo Joseph de Thellechea cura ministro de esta Doctrina de Sancta María Magdalena de Jaltepeque bauptizéa Jul[io], hijo de Matheo Nicolás y de María Rossa su mujer: fueron sus padrinos Jul[io] de la Cruz y Dominga de la Cruz natur[ales] y $\mathrm{Vez}[\mathrm{in}] \mathrm{os}$ de este dicho pueblo de Yuqhnduchi y p[or] q[ue] conste lo firmé

(Rúbrica)

Joseph de Thellechea

Transcripción

Foja 41 r.

En el pueblo de S[a]n Andrés Nuxinu en veinte y dos días del mes de enero de mill setecientos y diez y ocho años, baptizé solemnemente a Pascual, hijo de Juan López, y de Jacinta López, fue padrino D[o]n Carlos García Cano, vezino de el pueblo de Nochistlán, y por q[ue] conste lo firmé

(Rúbrica)

Jac[in] to Theobaldo González Amigón

En textos como los anteriormente transcritos podemos encontrar información, por ejemplo, de carácter filológico, sobre todo, si se encuentra relacionada con la toponimia o nombres de lugar en mixteco. El estudio de la toponimia mixteca tiene un interés particular porque se encuentra relacionada con el análisis de los glifos de nombres de lugar que aparecen escritos en códices y monumentos de la época prehispánica. 


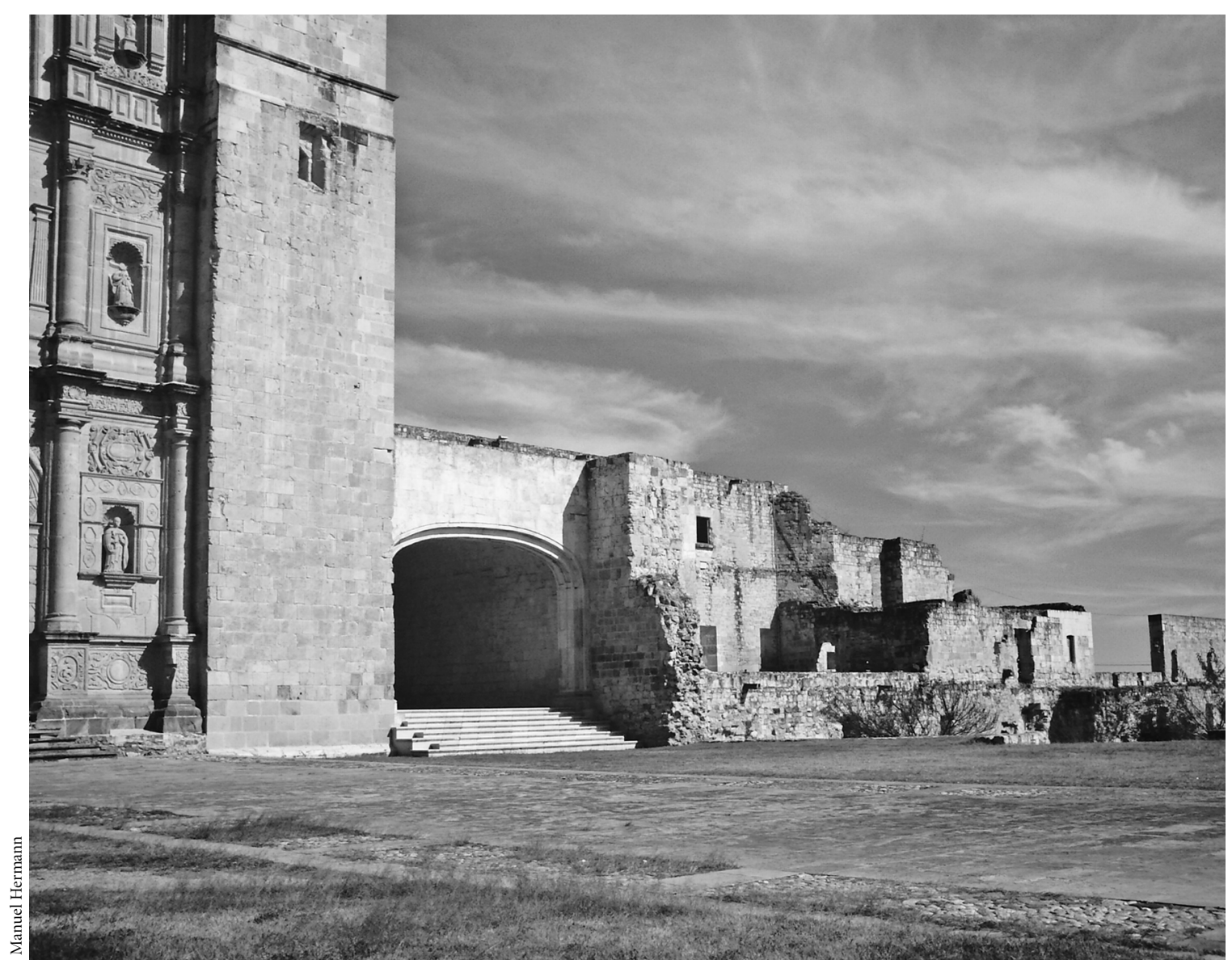

Entrada del convento de Yanhuitlán.

Si bien en estos ejemplos puede llegar a variar la ortografía de los topónimos, al menos contamos con registros que ayudan a dar un seguimiento del probable nombre que pudo haber tenido el pueblo en tiempos antiguos.

Desde luego, como hemos señalado, en los libros de bautizos se encuentra información sobre el estatus o clase social de los pobladores de Jaltepec y de los pueblos aledaños, así como de las relaciones sociales y económicas que se establecían entre ellos.

Transcripción

f. $52 \mathrm{v}$.

En doze días del mes de mayo de mill setezientos y veinte $y$ tres años, en la iglesia parroquial deste pueblo y cabeze- ra de Xaltepeque, yo el pa[dre] D[o]n Manuel Fernández del Rincón, sacerdote ministro deste d[ic]ho partido, baptizé solemnemente, puse óleo y chrisma a Fernando, hijo lexítimo de Vizente de Azebedo, mulato y de María Antonia, india, sirvientes del rancho de Dzumacuta, fueron sus padrinos Nicolás Francisco y Nicolasa López, sirvientes de d[i][c] ho rancho a quienes di a entender el parentesco espiritual y obligación de Doctrina y porque conste lo firmé

(rúbrica)

Man[ue]l Fernández del Rincón 


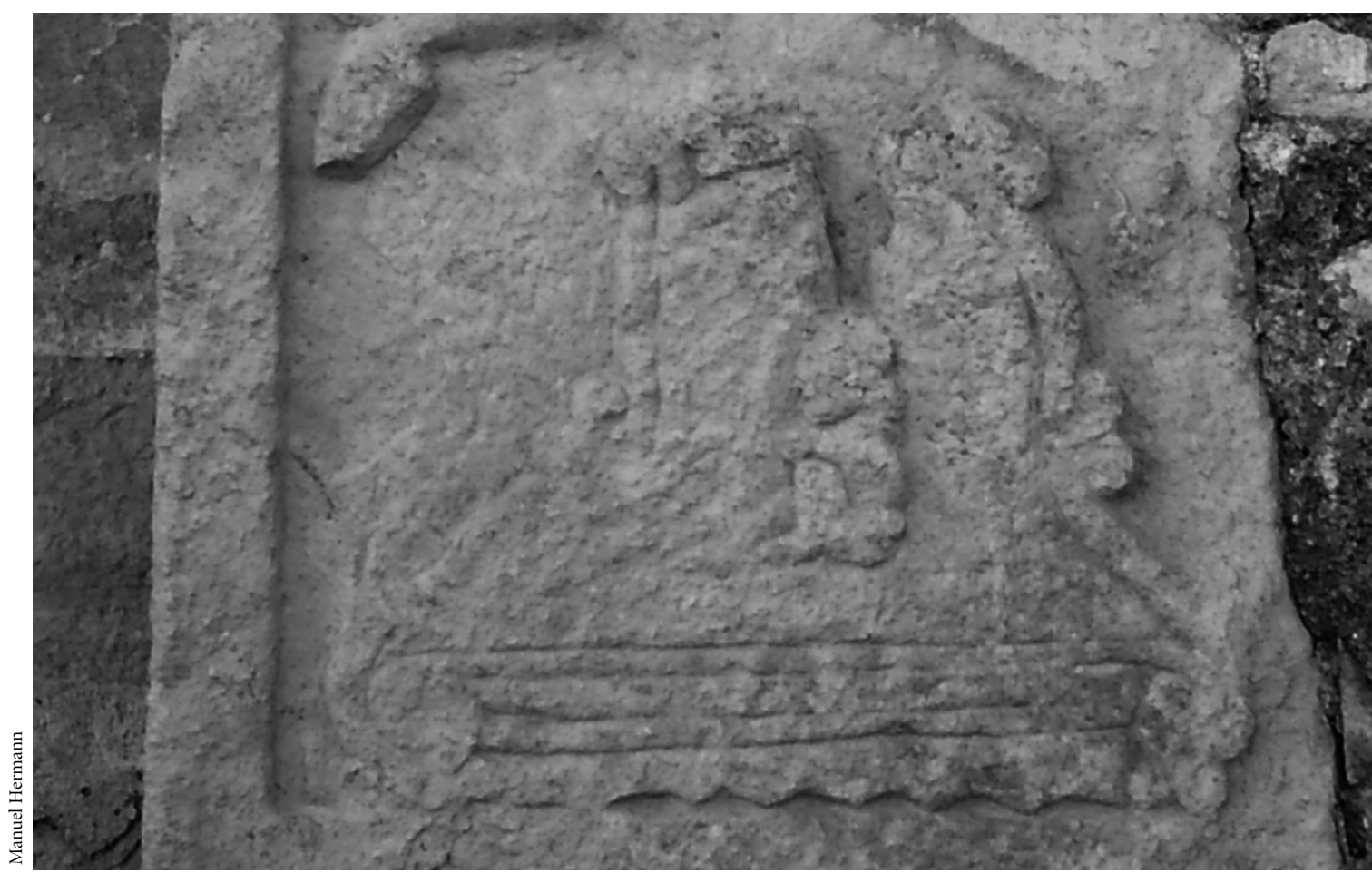

Hombre que nace de un cerro, relieve de Tilantongo.

Transcripción

f. $97 \mathrm{v}$.

En la iglesia parrochial de Jaltepeque en ocho días del mes de junio de mill setezientos y treinta y dos años, yo Manuel Fernández del Rincón, cura Beneficiado por su Majestad deste partido, baptizé solemnemente, puse óleo y chrisma a Paulino, hijo legítimo de Joseph Antonio, mulato, esclavo del L[icencia]do D[o]n Silvestre Muñoz, clérigo presbítero, y de Casilda de la Cruz, mestiza, fueron sus padrinos Joan María de Basaldua y Verónica María, todos sirvientes en la Hazienda que llaman Dzumacuta de d[ic]ho L[icencia]do D[o]n Silvestre Muñoz y les advertí la obligación de Doctrina y parentesco espiritual y porque conste lo firmé

(rúbrica)

Manuel F[ernánde]z del Rincón

Finalmente, presento a continuación el testimonio de una niña huérfana que queda a cargo de sus padrinos al no saberse quiénes habían sido sus padres legítimos.

\section{Transcripción \\ f. 106 v. y 107 r.}

En la iglesia parrochial del pueblo y cabezera de Jaltepeque, en veinte y seis días del mes de febrero de mill setezientos y treinta y cinco años, yo Manuel Fernández del Rincón, cura por su Majestad deste partido, Baptizé solemnemente, puse óleo y chrisma a Sebastiana, hija de padres no conocidos, fueron sus padrinos Domingo García y Paula García, naturales y vezinos desta $\mathrm{d}[\mathrm{ich}] \mathrm{a}$ cabezera, a quienes amonesté el parentesco espiritual y obligación de doctrina y porque conste los firmé

(rúbrica)

Manuel Fernández del Rincón

Aunque los ejemplos mostrados son muy pocos, al menos dejan constancia de la importancia de estos archivos y su utilidad para reconstruir la historia económica y social de los antiguos señoríos mixtecos. 